\title{
Dipeptidyl Peptidase-4 Inhibitor Administration Is Associated with Higher Eosinophil Counts and Batter Clinical Outcomes in Patients with Aorta Intramural Hematoma
}

\section{qu chen}

The First Hospital of China Medical University: The First Affiliated Hospital of China Medical University

\section{Dandan Jiang}

Xiamen University and Fujian Medical University Affiliated First Hospital: The First Affiliated Hospital of Xiamen University zhonggui shan ( $\nabla$ xmchenqu@163.com)

Xiamen sity and Fujian Medical University Affiliated First Hospital: The First Affiliated Hospital of Xiamen University https://orcid.org/0000-0003-3638-3640

\section{Research Article}

Keywords: IMH, Diabetes mellitus, Dipeptidyl Peptidase-4 Inhibitor, Intramural hematoma, Outcome

Posted Date: October 26th, 2021

DOI: https://doi.org/10.21203/rs.3.rs-1009971/v1

License: (c) (1) This work is licensed under a Creative Commons Attribution 4.0 International License. Read Full License 


\section{Abstract}

Objectives Investigating whether dipeptidyl peptidase-4 (DPP-4) inhibitors could influence clinical outcomes in intramural hematoma (IMH) patients with diabetes mellitus (DM).

Methods IMH patients who received a "wait and watch strategy" were included. Cox proportional hazard models were constructed to identify potential risk factors. A Kaplan-Meier survival analysis was used to estimate all-cause and aorta-related mortality during the follow-up period.

Results From January 2000 to December 2020, 1094 IMH patients were divided into group A ( $n=572$, IMH patients without $D M)$, group $B(n=191$, IMH patients with $D M$ and receiving oral antidiabetic drugs [without admission of DDP-4 inhibitors]) and group $C(n=331$, IMH patients with DM and receiving oral antidiabetic drugs [including admission of DDP-4 inhibitors]). Group $\mathrm{C}$ had the lowest rate of aorta-related adverse events $(6.4 \%)$, aorta-related mortality $(1.2 \%)$ and reintervention $(5.2 \%)$. Cox proportional hazard models revealed that lower eosinophil count (per 0.1, hazard ratio [HR], 0.61; 95\% confidence interval [Cl], $0.51-0.73, \mathrm{P}<0.001)$ and thicker hematoma thickness $(\mathrm{HR}, 1.22 ; 95 \% \mathrm{Cl}, 1.06-1.39, \mathrm{P}<0.001)$ were associated with higher occurrences of aorta-related adverse events. Lower eosinophil count (per 0.1, HR, $0.24 ; 95 \% \mathrm{Cl}, 0.15-0.40, \mathrm{P}<0.001)$, larger descending aorta diameters $(\mathrm{HR}, 1.12 ; 95 \% \mathrm{Cl}, 1.02-1.23, \mathrm{P}$ $<0.021)$, and thicker hematoma thickness $(\mathrm{HR}, 3.25 ; 95 \% \mathrm{Cl}, 2.36-4.46, \mathrm{P}<0.001)$ were also associated with increased aorta-related mortality. Kaplan-Meier survival analysis revealed a significant decrease in all-cause and aorta-related mortality in group $C(P<0.001)$.

Conclusions DPP-4 administration influences progression of IMH patients with $\mathrm{DM}$, leading to a lower rate of aorta-related adverse events, aorta-related mortality, and reinterventions.

\section{Introduction}

Diabetes mellitus (DM) is a major risk factor for cardiovascular disease ${ }^{1}$, but studies have found an inverse relationship between DM and the prevalence of aorta diseases ${ }^{2}$ and revealed the protective effects of DM on aorta disease ${ }^{3}$. However, other studies indicate that insulin treatment could diminish the protective effect of hyperglycemia in preventing the aortic aneurysm development process ${ }^{4}$ and the DM results in the impaired activation of the protective anti-inflammatory pathway in vascular inflammation ${ }^{5}$. Besides, long-lasting clinical hyperglycemia (> 10 years), but not prediabetes, independently played an important role in reducing abdominal aortic aneurysm risk ${ }^{6}$. In all, a possible explanation of the controversial roles of DM in aorta disease is that the protective effects of DM are the result of the requirement to overcome the damage of hyperglycemia on the aorta, and other factors such as the longterm administration of oral antidiabetic drugs may mitigate the aorta disease development.

Dipeptidyl Peptidase-4 (DPP-4) inhibitors are approved for use in type 2 DM, and currently, the vascular protective roles of DPP4 inhibitors have been described ${ }^{7}$. Kohashi et al. ${ }^{8}$ and Takahara et al. ${ }^{9}$ both indicated that DPP-4 inhibitor could suppress macrophage infiltration and abdominal aortic aneurysm 
formation. DPP-4 inhibitor administration may result in higher concentrations of the chemokine CCL-11 (eotaxin-1) and enhancing the recruitment of eosinophils to the vascular lesion ${ }^{10}$, and the eosinophils could release chemokines to regulate macrophage and monocyte polarization, block inflammatory activation in the aorta ${ }^{11}$, which may also trigger the normalization of vascular function such as restoring physiological perfusion, maintaining the normal oxygenation, and enhancing the angiogenesis process $^{12}$.

Acute aortic syndromes consist of three interrelated diseases: aortic dissection, penetrating aortic ulcer and intramural hematoma (IMH). In Asian countries, the "wait-and-watch strategy" (optimal medical therapy with blood pressure and pain control, serial imaging, and necessary surgery) is the first line of treatment ${ }^{1314}$ for IMH patients. Our previous study about the influence of DM on the clinical outcomes in IMH patients reveal the association between DM and better clinical outcomes and lower inflammatory biomarkers ${ }^{1516}$. But the influence of the DPP-4 inhibitor administration on the eosinophil in patients with $\mathrm{IMH}$ and corresponding clinical outcomes is unclear. So, in this retrospective study, we compared the clinical outcomes (aortic remodeling, clinical complications, and all-cause mortality) in IMH patients with and without type 2 DM. Besides, we also aimed to clarify the effects of DPP-4 inhibitor administration on leukocyte subtype and inflammatory biomarkers, and the potential association between these parameters and IMH patients' clinical outcomes.

\section{Methods}

\section{General Management Strategy and Study Protocol}

From January 2000 to December 2020, the study comprised IMH patients who received at least two weeks of "wait and watch strategy" (controlling pain, heart rate [60 beats per minute], and blood pressure [systolic blood pressure between 100 and $120 \mathrm{mmHg}$ ], receiving serial imaging plus necessary thoracic endovascular aortic repair [TEVAR]/open surgery) ${ }^{13}$. The Computed tomography angiography (CTA) examinations were scheduled as follows: on admission, two weeks after the onset of $\mathrm{IMH}$, and then annually, and in eventful cases, the CTA examinations were altered. The study was performed in accordance with the principles of the Declaration of Helsinki and the study protocol was approved by the Institutional Ethical Committee of Xiamen University (Xiamen, China). Because of the retrospective nature of the study, the patient consent for inclusion was waived.

To discuss the impact of oral antidiabetic drugs, especially the DPP-4 inhibitors, type 2 DM patients underwent insulin treatment before the onset of $\mathrm{IMH}$ and newly diagnosed type $2 \mathrm{DM}$ patients underwent long-term insulin treatment after the onset of IMH were excluded. Besides, patients with aortic connective tissue diseases (identified by pathology or genetic tests), traumatic aortic damage, and aortic valvular diseases were also excluded from the study. Additionally, we did not include patients with aortic rupture, ulcer-like projection (ULP) development on admission, lethal organ ischemia, unmanageable pain/hypertension, and those requiring emergency surgical or interventional therapy on admission.

Patients who refused medical treatment, those who did not have CTA images to estimate the evolution of 
$\mathrm{IMH}$, those who did not have complete laboratory data, and those who were lost to follow-up were regarded as missing data (See details of the CONSORT diagram in Figure 1).

The primary outcome was all-cause mortality. Secondary outcomes were aorta-related mortality (confirmed by autopsy or CTA examination) and aorta-related adverse events (hematoma thickening, ULP and dissection development, aortic aneurysm/pseudoaneurysm development) that required surgery/TEVAR.

\section{Blood Glucose Management}

The diagnostic criteria of type $2 \mathrm{DM}$ included: hemoglobin $\mathrm{A} 1 \mathrm{c}[\mathrm{HbA} 1 \mathrm{c}] \geq 6.5 \%$, fasting plasms glucose $\geq 126 \mathrm{mg} / \mathrm{dL}, 2$ hours plasma glucose $\geq 200 \mathrm{mg} / \mathrm{dL}$ ) ${ }^{17}$. During the perioperative period, the insulin pump with short-acting insulin was used to achieve rapid glucose control during the stay in the intensive care unit (with the help of a physician, D.J.) and then transfer to the oral antidiabetic medications drugs. The target blood glucose level included proper blood glucose levels in fasting and premeal states (80-130

$\mathrm{mg} / \mathrm{dL}$ ) and the postprandial state (less than $180 \mathrm{mg} / \mathrm{dL}$ ) ${ }^{17} 18$. The HA1c level would be measured every three months to determine whether glycemic targets had been met and maintained, and those who needed a combination of insulin treatment were excluded from the study.

\section{Statistical Analysis}

To compare categorical variables, the Pearson's Chi-Square test and Fisher's exact test were employed. To compare continuous variables, the Student's t-test, Welch's t-test, and Mann-Whitney U test were employed when appropriate. To check the normality, the Kolmogorov-Smirnov test was performed. Univariate and multivariable logistic regression analysis were used to identify independent risk variables linked to the occurrence of aorta-related adverse events. Cox proportional hazard models were used to assess the variables linked to aorta-related adverse events and aorta-related mortality during the follow-up. A Kaplan-Meier survival analysis with the log-rank test was used to assess the occurrence of aorta-related adverse events and aorta-related mortality. In multivariable analysis, factors with a P-value of less than 0.20 in univariate analyses were included. For statistical analysis, IBM SPSS Statistics for Windows Version 26.0 (IBM Corp., Armonk, New York) was utilized. Differences of $\mathrm{P}<0.05$ were defined as statistically significant.

\section{Results}

\section{Patient Characteristics}

From January 2000 to December 2020, a total of 1094 IMH patients who received the "wait-and-watch strategy" in a single institution were included in this study. These patients were divided into three groups, including group $A(n=572$, IMH patients without $D M)$, group $B(n=191, I M H$ patients with type 2 DM and receiving oral antidiabetic drugs [without admission of DDP-4 inhibitors]) and group $\mathrm{C}(\mathrm{n}=331, \mathrm{IMH}$ patients with type 2 DM and receiving oral antidiabetic drugs [including admission of DDP-4 inhibitors]). 
These three groups differed significantly in several covariables (including known risk factors for aortic diseases and known factors that could influence the progression and long-term outcomes of aortic diseases, Table 1, Supplement 1, and Supplement 2). Group B and group C had significantly higher BMI level and increased incidence rates of dyslipidemia than group $A$, while there were not significant differences among both groups (Supplement 2 and Supplement 3). As for laboratory test results, compared with the other two groups, group $\mathrm{C}$ had the lowest counts of white blood cells and neutrophils, the lowest neutrophil to lymphocyte ratio, as well as the lowest levels of C-reactive protein and D-dimer (Table 1, and Supplement 2). Group $\mathrm{C}$ also had the highest counts of lymphocytes and eosinophils among the three groups, and the pairwise comparison results also demonstrated the significant differences among the three groups (Supplement 2). In the measurement results of the aorta, interestingly, group $\mathrm{C}$ had the largest ascending aorta diameter compared to groups $\mathrm{A}$ and $\mathrm{B}$, while the larger ascending aorta diameter $(>4.0 \mathrm{~cm})$ had been wildly accepted as a risk factor for lethal progression of aorta diseases ${ }^{19}$. The descending aorta diameter in group $\mathrm{B}$ and $\mathrm{C}$ was also significantly larger than in group A. But, as for the maximum hematoma thickness, another well-known predictor of intramural hematoma lethal progression ${ }^{20}$, group $\mathrm{C}$ had the smaller thickness while group $\mathrm{A}$ had the significantly thickest hematoma thickness compared to the other two groups (Table 1, and Supplement 2).

\section{Disease Progression, Treatment, Clinical Outcomes, and Late Follow-Up}

The details of disease progression, treatment, clinical outcomes, and late follow-up results were summarized in Table 2 and Supplement 3. The occurrence rate of aorta-related adverse events during the acute phase was obviously higher in group $A(16.6 \%)$ and group $C$ had the lowest compared occurrence rate (3.0\%) than in groups $A$ and $B$ (Table 2, and Supplement 3 ). The most common aorta-related adverse event was the development of ULP, and up to $14.2 \%$ of patients in group A suffered from it, while group $C$ had a comparatively lower rate of ULP development (2.1\%). Compared to group A and group B, fewer patients in group $C$ received surgery/TEVAR treatment during the acute phase $(0 \%$ and $3 \%)$, while the mortality after the acute phase surgery/TEVAR was similar among the three groups (from $10.0 \%$ to 13.3\%) (more details in Table 2 and Supplement 3).

After discharge, the late follow-up comprised 1079 patients, and the median follow-up times for each group were as follows: group A (44.2 months, 95\% confidence interval [Cl], 42.0-46.4 months), group B (43.0 months, $95 \% \mathrm{Cl}, 38.1-47.9$ months) and group C ( 40.6 months, $95 \% \mathrm{Cl}, 36.9-44.4$ months). $93.6 \%$ of patients in group $\mathrm{C}$ had a resolution of the hematoma or stable hematoma, which were dramatically higher than in group $A$ and group $B$, while the occurrence rate of aorta-related adverse events was up to $29.8 \%$ in group $A$ and $12.7 \%$ in group B. The development of the ULP was still the most common aortarelated adverse event and affected $22.7 \%$ of the patients in group $A$, which was significantly higher than in group $B$ and group $C$ (Table 2). Group A also had a greater reintervention rate during the follow-up period than the other two groups. Compared with group $B$, the reintervention rate in group $C$ was significantly lower (11.1\% vs 5.2\%, Table 2 and Supplement 3 ). 
There were significant differences in all-cause and aorta-related mortality among the three groups during the follow-up period. Group $C$ had significantly lower all-cause mortality (4.2\%) and aorta related mortality (3.0\%) than group A and group B, while there was not a significant difference among group A and group $B$ (Table 2). The Kaplan-Meier survival analysis revealed a significant decrease in the all-cause and aortarelated mortality rates in the group $\mathrm{C}$ compared with that in the group $\mathrm{B}$ and $\mathrm{C}(P<0.001$, Figure 2).

\section{Variables Associated with Aorta-related Adverse Events and Aorta-related Mortality}

Logistic regression analyses indicated that lower eosinophil count (per 0.1, odds ratio [OR], 0.12; $95 \% \mathrm{Cl}$, 0.06-0.22, $P<0.001$ ), higher C-reactive protein levels (CRP, OR, 1.10; 95\% Cl, 1.05-1.14, $P<0.001$ ), larger ascending aorta diameters $(\mathrm{OR}, 1.41 ; 95 \% \mathrm{Cl}, 1.18-1.68, P<0.001)$, larger descending aorta diameters (OR, $1.52 ; 95 \% \mathrm{Cl}, 1.31-1.76, P<0.001)$ and thicker hematoma thickness (OR, 2.00; 95\% Cl, 1.43-2.81, $P<0.001)$ were found to be significantly associated with aorta-related adverse events acute phase (Table 3 ). Cox proportional hazard models revealed that lower eosinophil count (per 0.1 , hazard ratio [HR], $0.61 ; 95 \% \mathrm{Cl}$, 0.51-0.73, $P<0.001)$ and thicker hematoma thickness (HR, 1.22; 95\% $\mathrm{Cl}, 1.06-1.39, P<0.001)$ were associated with higher occurrence rate of aorta-related adverse events during follow-up period. And lower eosinophil count (per $0.1, \mathrm{HR}, 0.24 ; 95 \% \mathrm{Cl}, 0.15-0.40, P<0.001)$, larger descending aorta diameters (HR, $1.12 ; 95 \% \mathrm{Cl}, 1.02-1.23, P=0.021$ ), and thicker hematoma thickness (HR, 3.25; 95\% $\mathrm{Cl}, 2.36-4.46, P<0.001$ ) were significantly associated with aorta-related mortality during the follow-up period (see more details in

Table3).

\section{Discussion}

Because of the lower mortality after early medical therapy compared to those with aortic dissection, the "wait and watch strategy" is the first line treatment for patients with IMH in Asian countries ${ }^{13}{ }^{14}$. However, the evolution of $\mathrm{IMH}$ is very dynamic and unpredictable, ranging from complete resolution to abrupt rupture ${ }^{1321}$, despite the fact that numerous predictors of IMH evolution, such as maximum aortic diameter $(\geq 4.0 \mathrm{~cm})^{19}$, hematoma thickness $(\geq 10 \mathrm{~mm})^{20}$, ULP development ${ }^{22}$ and an elevated CRP level $(7.2 \mathrm{mg} / \mathrm{dL})^{23}$, have been summarized. Moreover, for type A IMH, the development of classic aortic dissection (19\%) and retrograde type A aortic dissection (27\%) are very common fatal evolutions after receiving the "wait-and-watch strategy", and the need for further TEVAR/surgery was up to $30 \%$ within the first 6 months ${ }^{1424}$. Additionally, for type B IMH, Moral et al found that $10 \%$ of type B IMH patients, who developed ULP in the acute phase, were correlated with $91 \%$ of aorta-related adverse events and a $36 \%$ mortality $22.43 \%$ of type B IMH patients had TEVAR therapy in the first two weeks following diagnosis due to the visibility of an entry rip or aneurysm growth, while $19 \%$ of type B IMH patients had TEVAR in the first year ${ }^{25}$. In our study, in group A (IMH patients without DM), the occurrence of aorta-related adverse events, aorta-related mortality, and the rate of TEVAR/surgery treatment were similar to those reported by previous studies ${ }^{13} 14222425$. As for group B (IMH patients with type 2 DM and receiving oral antidiabetic drugs [without admission of DDP-4 inhibitors]) and group C (IMH patients with type 2 DM and receiving oral antidiabetic drugs [including admission of DDP-4 inhibitors]), the occurrence of aorta-related adverse 
events, the aorta-related mortality, and the rate of TEVAR/surgery treatment were significantly lower than group A, even though these two groups had larger aorta diameters.

Although numerous studies have found an inverse relationship between DM and the prevalence of aorta diseases and have tried to demonstrate the protective effects of DM on aorta disease development ${ }^{23}$, as DM requires life-long antidiabetic treatment, long-term administration of oral antidiabetic drugs may mitigate the development of aorta disease. Epidemiological investigations have indicated that the mechanisms resulting a protective effect of DM on aorta disease development are associated not only to DM pathophysiology but also to antidiabetic treatments. The use of antidiabetic medications was related with a 56\% reduction in abdominal aorta aneurysm growth rate in a trial of 1269 individuals, and this association was independent of confounding variables such as other treatment agents ${ }^{26}$. Other studies also have established the negative relationship between metformin administration and aorta aneurysm enlargement and growth ${ }^{27}$. Furthermore, a nested case-control study involving 4468 abdominal aorta aneurysm patients and 4468 matched controls found that metformin, sulfonylurea, and thiazolidinedione administration was related to a reduced risk of aneurysm development ${ }^{28}$. But metformin administration was shown to have no significant link to the risk of rupture of abdominal aorta aneurysm ${ }^{29}$. In our study, DM patients who received metformin, sulfonylurea, and thiazolidinedione without DPP-4 inhibitors were included in group $B$, and remarkably, there were no significant differences in all-cause and aorta-related mortality between groups A and B during the follow-up period (Table 2 and Figure 2), which was similar to the report of Kristensen and colleagues ${ }^{29}$.

Higher eosinophil counts are possibly related to better clinical outcomes in IMH patients by promoting the thrombosis process of the aortic lesion. The probable pathogenic mechanism of IMH might well be described from two perspectives: the rupture of the vasa vasorum in the aorta's medium and thrombosis inside the intimal layer, with no entrance tears ${ }^{13}$. The balance between thrombosis thrombolysis and thrombolysis probably plays a critical role in IMH progression. A proper thrombosis process may lead to more favorable outcomes, such as hematoma stabilization or absorption. And vice versa, disrupting the balance and amplifying the thrombolysis process may lead to ULP/dissection development, aortic aneurysm expansion, and aortic rupture. Until recently, numerous clinical observations implicated that eosinophil activation in atherosclerosis and thrombosis ${ }^{30} 31$. The eosinophils contribute to atherosclerotic plaque formation and thrombosis through an interplay with platelets because eosinophils could enhance von Willebrand factor exposure on endothelial cells and augment platelet adhesion ${ }^{32}$. Moreover, A study revealed that eosinophils infiltrating the aortic lesion could release chemokines and play a protective role in abdominal aortic aneurysm progression by regulating macrophage and monocyte polarization and blocking NF-KB activation in the aortic wall inflammatory process, vascular smooth muscle cells, and endothelial cell dysfunction ${ }^{11}$, which may also trigger the normalization of vascular function such as restoring physiological perfusion, maintaining the normal oxygenation, and enhancing the angiogenesis process ${ }^{12}$. These may all be attributed to the maintenance of a proper thrombosis process in IMH of group $\mathrm{C}$, which may lead to better clinical outcomes and explain why this group had the thinnest hematoma thickness even though they had the largest aorta diameter. 
Moreover, DPP-4 inhibitor administration probably induces the accumulation of eosinophils by resulting in higher concentrations of the chemokine CCL-11 (eotaxin-1). The activating axis of interleukin-5, CCL-11 (eotaxin-1) and CC-chemokine receptor 3 (CCR3, the eotaxin-family receptor) is required for eosinophil accumulation $^{33}$, and there is also an overexpression of the eosinophil chemoattractant and activator CCL11 (eotaxin-1) in the vascular lesion, which may contribute to thrombosis formation ${ }^{34}$. Activation of DPP4-mediated truncation may mediate the sensitive of CCL11 binding to the chemokine receptor (CCR3) expressed on the surface of eosinophils, and over activation of DPP4 most likely results in impaired eosinophil chemotaxis ${ }^{35}$. In the animal experiment, after DPP4 inhibitor treatment, there were higher levels of CCL11 and increased concentrations of IL-5 ${ }^{10}$. In other animal models, the application of DPP-4 inhibitors could suppress macrophage infiltration and decrease abdominal aortic aneurysm formation ${ }^{78}$. In our study, only group $C$ received the DPP-4 inhibitor, and this group had the statistically highest level of eosinophil count than the other two groups, and higher eosinophils levels are also associated with lower aorta-related adverse events and mortality during the follow-up period.

Additionally, the group A had higher D-dimer levels and neutrophil to lymphocyte ratio (NLR). D-dimer is not a specific biomarker for acute aortic syndrome because it can be elevated in other conditions such as acute myocardial infarction and acute pulmonary embolism, but it is highly sensitive for ruling out classical acute aortic syndrome within the first 6 hours of symptom onset ${ }^{36}{ }^{37}$. The NLR value reflected the severity of the non-specific inflammatory lesion, which is characterized by an increase in neutrophils and a decrease in lymphocytes, that the increased NLR may be used to predict worse outcomes and hospital mortality in patients with type A aorta dissection ${ }^{38}$. Furthermore, an increased preoperative NLR ratio may predict early adverse outcomes in patients with uncomplicated type $B$ aortic dissection undergoing TEVAR treatment ${ }^{39}$. In all, further studies are needed to confirm the potential value of D-dimer and NLR in predicting the progression of IMH patients.

There are several limitations to this study. First, since DM is a lifelong disease, a long-time follow-up is necessary. To estimate the influence of DM and different oral antidiabetic drugs on IMH progression, it requires a future longitudinal prospective investigation with a multicenter cooperation focuses on more patients and different schemes of oral antidiabetic drugs. Second, since DPP-4 inhibitor administration probably induces the accumulation of eosinophils by resulting in higher concentrations of the chemokine CCL-11 (eotaxin-1), further studies with a measurement of CCL-11 concentration and expression from blood samples or aortic tissue are required to demonstrate this potential mechanism. Third, in our study, those who required emergency surgery/TEVAR treatment were excluded, and techniques (such as TEVAR devices and arch reconstruction methods) probably affect patient outcomes. Further studies are required for a more standardized and uniform management strategy to estimate the influence of these potential risk factors.

\section{Conclusion}


Dipeptidyl peptidase-4 inhibitor administration influences intramural hematoma progression and leads to a lower aorta-related adverse events rate, aorta-related mortality, and reinterventions. Variables associated with lower aorta-related adverse events during the follow-up period included lower eosinophil count and thicker hematoma thickness. Furthermore, lower eosinophil count, larger descending aorta diameter, and thicker hematoma thickness are all associated with aorta-related mortality during the follow-up period.

\section{Abbreviations}

CTA: Computed tomography angiography

CRP: C-reactive protein

DDP-4: Dipeptidyl peptidase-4

DM: Diabetes mellitus

IMH: Intramural hematoma

NLR: Neutrophil to lymphocyte ratio

TEVAR: Thoracic endovascular aortic repair

ULP: Ulcer-like projection

\section{Declarations}

Ethics approval and consent to participate: The Institutional Ethical Committee of Xiamen University (the number of ethical approvals: XMFH201805030c) approved the study protocol and publication of data. Because of the retrospective nature of the study, the patient consent for inclusion was waived.

Consent for publication: Applicable

Competing interests: The authors of this manuscript have no relationships with the industry to disclose.

Availability of data and materials: The raw data required to reproduce these findings cannot be shared at this time as the data also forms part of an ongoing study.

Disclosures: The authors of this manuscript have no relationships with the industry to disclose.

Funding: None.

\section{Authors' contributions}

Conception and design: QC, DJ, ZS. 
Analysis and interpretation: QC, ZS.

Data collection: QC, DJ.

Writing the article: QC, DJ.

Critical revision of the article: ZS.

Final approval of the article: QC, DJ, ZS

Agreement to be accountable: QC, DJ, ZS

Statistical analysis: QC, DJ.

Acknowledgement

Dr. Dandan Jiang, a good wife and a loving mother of her family, is thanked by the authors for her contributions to data gathering and statistical analysis, as well as for giving emotional support to $\mathrm{Dr}$. Qu Chen.

\section{References}

1 Cosentino F, Grant PJ, Aboyans V, Bailey CJ, Ceriello A, Delgado V, et al. 2019 ESC Guidelines on diabetes, prediabetes, and cardiovascular diseases developed in collaboration with the EASD. Eur Heart J. 2019;1-69.

2 Nienaber CA. Diabetes mellitus and thoracic aortic disease: are people with diabetes mellitus protected from acute aortic dissection? J Am Heart Assoc. 2012;1:e001404.

3 Juliette Raffort, Fabien Lareyre, Marc Clément, Réda Hassen-Khodja, Giulia Chinetti, Ziad Mallat.Diabetes and aortic aneurysm: current state of the art. Cardiovasc Res. 2018 ;114:1702-1713.

4 Miyama N, Dua MM, Yeung JJ, Schultz GM, Asagami T, Sho E, et al. Hyperglycemia limits experimental aortic aneurysm progression. J Vasc Surg. 2010;52: 975-83.

5 Rask-Madsen C, King GL. Vascular complications of diabetes: mechanisms of injury and protective factors. Cell Metab 2013;17:20-33.

6 Xuejuan Ning, Ning Ding, Shoshana H Ballew, Caitlin W Hicks, Josef Coresh, Elizabeth Selvin, et al. Diabetes, its duration, and the long-term risk of abdominal aortic aneurysm: The Atherosclerosis Risk in Communities (ARIC) Study. Atherosclerosis. 2020; 313:137-143.

7 Liu H, Guo L, Xing J, Li P, Sang H, Hu X, et al. The protective role of DPP4 inhibitors in atherosclerosis. Eur J Pharmacol. 2020, 15;875:173037. 
8 Kyoko Kohashi, Munenori Hiromura, Yusaku Mori, Michishige Terasaki, Takuya Watanabe, Hideki Kushima, et al. A Dipeptidyl Peptidase-4 Inhibitor but not Incretins Suppresses Abdominal Aortic Aneurysms in Angiotensin II-Infused Apolipoprotein E-Null Mice. J Atheroscler Thromb. 2016;23:441-54.

9 Yusuke Takahara, Tomotake Tokunou, Toshihiro Ichiki. Suppression of Abdominal Aortic Aneurysm Formation in Mice by Teneligliptin, a Dipeptidyl Peptidase-4 Inhibitor. J Atheroscler Thromb. 2018;25:698-708.

10 Clémence Hollande, Jeremy Boussier, James Ziai, Tamaki Nozawa, Vincent Bondet, Wilson Phung, et al. Inhibition of the dipeptidyl peptidase DPP4 (CD26) reveals IL-33-dependent eosinophil-mediated control of tumor growth.

Nat Immunol. 2019 Mar,20(3):257-264. doi: 10.1038/s41590-019-0321-5. Epub 2019 Feb 18.

11 Cong-Lin Liu, Xin Liu, Yuanyuan Zhang, Jing Liu, Chongzhe Yang, Songyuan Luo, et al. Eosinophils Protect Mice From Angiotensin-II Perfusion-Induced Abdominal Aortic Aneurysm. Circ Res. 2021;128:188-202.

12 Grisaru-Tal S, Itan M, Klion AD, Munitz A. A new dawn for eosinophils in the tumour microenvironment. Nat Rev Cancer. 2020;20:594-607.

13 Erbel R, Aboyans V, Boileau C, Bossone E, Bartolomeo RD, Eggebrecht $\mathrm{H}$, et al. ESC Committee for Practice Guidelines. 2014 ESC Guidelines on the diagnosis and treatment of aortic diseases: document covering acute and chronic aortic diseases of the thoracic and abdominal aorta of the adult. The Task Force for the Diagnosis and Treatment of Aortic Diseases of the European Society of Cardiology (ESC). Eur Heart J 2014; 35: 2873-2926.

14 Song JK, Yim JH, Ahn JM, Kim DH, Kang JW, Lee TY, et al. Outcomes of patients with acute type A aortic intramural hematoma. Circulation 2009;120: 2046-2052.

15 Chen Q, Jiang D, Kuang F, Yang F, Shan Z. Outcomes of type A intramural hematoma: Influence of diabetes mellitus. J Card Surg. 2020;35:1811-1821.

16 Qu Chen, Dandan Jiang, Feng Kuang, Fan Yang, Zhonggui Shan. Outcomes of uncomplicated Type B intramural hematoma patients with Type 2 diabetes mellitus. J Card Surg. 2021;36:1209-1218.

17 American Diabetes Association. 2. Classification and diagnosis of diabetes: Standards of Medical Care in Diabetes-2019. Diabetes Care. 2019; 42: S13-S28.

18 Lazar HL, McDonnell M, Chipkin SR, Furnary AP, Engelman RM, Sadhu AR, et al. The Society of Thoracic Surgeons practice guideline series: Blood glucose management during adult cardiac surgery. Ann Thorac Surg. 2009;87: 663-9. 
19 Williams JB, Andersen ND, Bhattacharya SD, Scheer E, Piccini JP, McCann RL, et al. Retrograde ascending aortic dissection as an early complication of thoracic endovascular aortic repair. J Vasc Surg. 2012;55(5):1255-1262.

20 Sueyoshi E, Imada T, Sakamoto I, Matsuoka Y, Hayashi K. Analysis of predictive factors for progression of type B aortic intramural hematoma with computed tomography. J Vasc Surg. 2002;35:1179-1183.

21 V Riambau, D Böckler, J Brunkwall, P Cao, R Chiesa, G Coppi, et al. Editor's Choice-Management of Descending Thoracic Aorta Diseases Clinical Practice Guidelines of the European Society for Vascular Surgery (ESVS). Eur J Vasc Endovasc Surg. 53, 2017:4-52.

22 Moral S, Cuéllar H, Avegliano G, Ballesteros E, Maria Teresa Salcedo, Ignacio Ferreira-González, et al. Clinical implications of focal intimal disruption in patients with type b intramural hematoma. J Am Coll Cardiol. 2017;69:28-39.

23 Kitai T, Kaji S, Kim K, Natsuhiko E, Tomoko T, Makoto K, et al. Prognostic value of sustained elevated C-reactive protein levels in patients with acute aortic intramural hematoma. $\mathrm{J}$ Thorac Cardiovasc Surg. 2014;147(1):326-331.

24 Canaud L, Ozdemir BA, Patterson BO, Holt PJ, Loftus IM, Thompson MM. Retrograde aortic dissection after thoracic endovascular aortic repair. Ann Surg. 2014;260:389-39.

25 Schoenhoff FS, Zanchin C, Czerny M, Makaloski V, Gahl B, Carrel T et al. Aorta related and allcause mortality in patients with aortic intramural haematoma. Eur J Vasc Endovasc Surg. 2017; 54:447453.

26 Thompson A, Cooper JA, Fabricius M, Humphries SE, Ashton HA, Hafez H. Ananalysis of drug modulation of abdominal aortic aneurysm growth through 25 years of surveillance. J Vasc Surg 2010;52:55-61.

27 Fujimura $\mathrm{N}$, Xiong J, Kettler EB, Xuan $\mathrm{H}$, Glover $\mathrm{KJ}$, et al. Metformin treatment status and abdominal aortic aneurysm disease progression. J Vasc Surg 2016;64:46-54.

28 Hsu CY, Su YW, Chen YT, Tsai SH, Chang CC, Li SY, et al. Association between use of oralantidiabetic drugs and the risk of aortic aneurysm: a nested case-control analysis. Cardiovasc Diabetol 2016;15:125.

29 Kristensen KL, Pottegard A, Hallas J, Rasmussen LM, Lindholt JS. Metformin treatment does not affect the risk of ruptured abdominal aortic aneurysms. J Vasc Surg 2017;66:768-774.

30 Jiang P, Wang DZ, Ren YL, Cai JP, Chen BX. Significance of eosinophil accumulation in the thrombus and decrease in peripheral blood in patients with acute coronary syndrome. Coron Artery Dis. 2015;26(2): 
101-106.

31 Sakai T, Inoue S, Matsuyama TA, et al. Eosinophils may be involved in thrombus growth in acute coronary syndrome. Int Heart J. 2009;50(3):267-277.

32 Charlotte Marx, Julia Novotny, Danby Salbeck, Katie R Zellner, Leo Nicolai, Kami Pekayvaz, et al. Eosinophil-platelet interactions promote atherosclerosis and stabilize thrombosis with eosinophil extracellular traps. Blood. 2019;134:1859-1872.

33 Ljubov Simson, Julia I Ellyard, Lindsay A Dent, Klaus I Matthaei, Marc E Rothenberg, Paul S Foster, et al. Regulation of carcinogenesis by IL-5 and CCL11: a potential role for eosinophils in tumor immune surveillance. J Immunol. 2007;178:4222-9.

34 Pertiwi KR, de Boer OJ, Mackaaij C, Dara R Pabittei, Robbert J de Winter, Xiaofei Li 4, et al. Extracellular traps derived from macrophages, mast cells, eosinophils and neutrophils are generated in a timedependent manner during atherothrombosis. J Pathol. 2018;247(4): 505-512.

35 S Struyf, P Proost, D Schols, E De Clercq, G Opdenakker, J P Lenaerts, et al. CD26/dipeptidylpeptidase IV down-regulates the eosinophil chemotactic potency, but not the anti-HIV activity of human eotaxin by affecting its interaction with CC chemokine receptor 3. J Immunol. 1999;162:4903-9.

36 Watanabe H, Horita N, Shibata Y, Minegishi S, Ota E, Kaneko T. Diagnostic test accuracy of Ddimer for acute aortic syndrome: systematic review and metaanalysis of 22 studies with 5000 subjects. Sci Rep 2016;6:26893.

37 Suzuki T, Bossone E, Sawaki D, Janosi RA, Erbel R, Eagle K, Nagai R. Biomarkers of aortic diseases. Am Heart J 2013;165:15-25.

38 Mehmet Emin Kalkan, Ali Kemal Kalkan, Ahmet Gündeş, Mehmed Yanartaş, Semi Oztürk, Ahmet Seyfeddin Gurbuz, et al. Neutrophil to lymphocyte ratio: a novel marker for predicting hospital mortality of patients with acute type A aortic dissection. Perfusion. 2017;32:321-327.

39 Hongqiao Zhu, Lei Zhang, Taiping Liang, Yiming Li, Jian Zhou, Zaiping Jing. Elevated preoperative neutrophil-to-lymphocyte ratio predicts early adverse outcomes in uncomplicated type B aortic dissection undergoing TEVAR BMC Cardiovasc Disord. 2021;21:95.

\section{Tables}

Table 1 Baseline Characteristics ${ }^{a}$ 


\begin{tabular}{|c|c|c|c|c|}
\hline Variables & $\begin{array}{l}\text { Group A } \\
(\mathrm{n}=572)\end{array}$ & $\begin{array}{l}\text { Group B } \\
(\mathrm{n}=191)\end{array}$ & $\begin{array}{l}\text { Group C } \\
(\mathrm{n}=331)\end{array}$ & $P$ value \\
\hline Age, years & $64(54,73)$ & $64(53,74)$ & $64(55,73)$ & 0.419 \\
\hline BMI, $\mathrm{kg} / \mathrm{m}^{2}$ & $\begin{array}{l}24.4(22.3 \\
26.7)\end{array}$ & $\begin{array}{l}26.6(23.9, \\
29.0)\end{array}$ & $\begin{array}{l}26.3(23.5, \\
28.9)\end{array}$ & $<0.001^{b}$ \\
\hline Gender, sex & & & & 0.548 \\
\hline Male, n (\%) & $310(54.2 \%)$ & $95(49.7 \%)$ & $173(52.3 \%)$ & \\
\hline Female, n (\%) & $262(45.8 \%)$ & $96(50.3 \%)$ & $158(47.7 \%)$ & \\
\hline Aorta intramural hematoma ${ }^{c}$ & & & & $<0.001$ \\
\hline Type A & $402(70.3 \%)$ & $122(63.9 \%)$ & $73(22.1 \%)$ & \\
\hline Type B & $170(29.7 \%)$ & $69(36.1 \%)$ & $258(77.9 \%)$ & \\
\hline \multicolumn{5}{|l|}{ Concomitant diseases } \\
\hline Smoking, n (\%) & $392(68.5 \%)$ & 139 (72.8\%) & $225(68.0 \%)$ & 0.475 \\
\hline Drinking, n (\%) & $396(69.2 \%)$ & $143(74.9 \%)$ & $246(74.3 \%)$ & 0.151 \\
\hline Hypertension, n (\%) & $423(74.0 \%)$ & $139(72.8 \%)$ & $247(74.6 \%)$ & 0.898 \\
\hline Dyslipidemia, n (\%) & $220(38.5 \%)$ & $168(88.0 \%)$ & $287(86.7 \%)$ & $<0.001$ \\
\hline $\begin{array}{l}\text { Coronary heart disease, } \mathrm{n} \\
\text { (\%) }\end{array}$ & $184(32.2 \%)$ & $76(39.8 \%)$ & $128(38.7 \%)$ & 0.056 \\
\hline Obstructive Sleep Apnea & $421(73.6 \%)$ & $148(77.5 \%)$ & $242(73.1 \%)$ & 0.500 \\
\hline Renal Failure, n (\%) & $9(1.6 \%)$ & $2(1.0 \%)$ & $7(2.1 \%)$ & 0.640 \\
\hline Stroke, n (\%) & $34(5.9 \%)$ & 7 (3.7\%) & $14(4.2 \%)$ & 0.334 \\
\hline Peripheral ischemia, $\mathrm{n}(\%)$ & $18(3.1 \%)$ & $13(6.8 \%)$ & $18(5.4 \%)$ & 0.064 \\
\hline \multicolumn{5}{|l|}{ Antihypertensive medications } \\
\hline ACEI/ARB, n (\%) & $525(91.8 \%)$ & $176(92.1 \%)$ & $300(90.6 \%)$ & 0.786 \\
\hline B-blockers, n (\%) & $520(90.9 \%)$ & $174(91.1 \%)$ & $301(90.9 \%)$ & 0.997 \\
\hline Calcium antagonists, $\mathrm{n}(\%)$ & $261(45.6 \%)$ & $102(53.4 \%)$ & $174(52.6 \%)$ & 0.056 \\
\hline Diuretic, n (\%) & $137(24.0 \%)$ & $59(30.9 \%)$ & $95(28.7 \%)$ & 0.100 \\
\hline Urapidil, n (\%) & $499(87.2 \%)$ & $161(84.3 \%)$ & $286(86.4 \%)$ & 0.588 \\
\hline Nitrates, n (\%) & $179(31.3 \%)$ & 73 (38.2\%) & $125(37.8 \%)$ & 0.069 \\
\hline \multicolumn{5}{|l|}{ Laboratory test on admission } \\
\hline White blood cell (10^9/L) & $\begin{array}{c}11.8(10.3 \\
13.5)\end{array}$ & $\begin{array}{c}11.5(9.8 \\
12.9)\end{array}$ & $8.5(7.2,9.7)$ & $<0.001^{b}$ \\
\hline Neutrophils (10^9/L) & $10.6(9.1,12.4)$ & $9.8(8.3,11.4)$ & $6.3(4.9,7.5)$ & $<0.001^{b}$ \\
\hline Lymphocyte (10^9/L) & $\begin{array}{l}0.79(0.60 \\
0.96)\end{array}$ & $\begin{array}{l}1.19(0.84 \\
1.44)\end{array}$ & $\begin{array}{c}1.51(1.34 \\
1.77)\end{array}$ & $<0.001^{b}$ \\
\hline Eosinophils $\left(10^{\wedge} 9 / \mathrm{L}\right)$ & $\begin{array}{l}0.05(0.020 \\
0.080)\end{array}$ & $\begin{array}{l}0.11(0.055 \\
0.17)\end{array}$ & $\begin{array}{l}0.30(0.27 \\
0.33)\end{array}$ & $<0.001^{b}$ \\
\hline Basophils (10^9/L) & $\begin{array}{l}0.03(0.01 \\
0.05)\end{array}$ & $\begin{array}{l}0.03(0.01 \\
0.05)\end{array}$ & $\begin{array}{l}0.03(0.02 \\
0.05)\end{array}$ & 0.432 \\
\hline Monocytes (10^9/L) & $\begin{array}{l}0.34(0.22 \\
0.47)\end{array}$ & $\begin{array}{l}0.32(0.23 \\
0.47)\end{array}$ & $\begin{array}{l}0.35(0.23 \\
0.48)\end{array}$ & 0.759 \\
\hline Platelet $\left(10^{\wedge} 9 / \mathrm{L}\right)$ & $238(180,295)$ & $\begin{array}{l}230(178 \\
296)\end{array}$ & $\begin{array}{l}238(179 \\
297)\end{array}$ & 0.849 \\
\hline C-reactive protein $(\mathrm{mg} / \mathrm{L})$ & $\begin{array}{l}35.2(22.2 \\
47.72)\end{array}$ & $\begin{array}{l}32.7(18.9 \\
\quad 41.4)\end{array}$ & $\begin{array}{l}18.0(11.8 \\
23.7)\end{array}$ & $<0.001^{b}$ \\
\hline D-dimer (ug/mL) & $\begin{array}{l}3.74(3.25 \\
4.24)\end{array}$ & $\begin{array}{l}3.03(2.42 \\
3.52)\end{array}$ & $\begin{array}{l}1.40(1.06, \\
1.83)\end{array}$ & $<0.001^{b}$ \\
\hline $\begin{array}{l}\text { Neutrophil to lymphocyte } \\
\text { ratio }\end{array}$ & $\begin{array}{l}13.60(10.95 \\
17.60)\end{array}$ & $\begin{array}{l}8.21(6.77 \\
11.92)\end{array}$ & $\begin{array}{l}4.07(3.24 \\
5.02)\end{array}$ & $<0.001^{b}$ \\
\hline
\end{tabular}

Geometric measurements

Diameter of ascending

38.1 (35.7,

40.5 (37.5,

41.6 (39.1, 


\begin{tabular}{ccccc} 
aorta $(\mathrm{mm})$ & $40.5)$ & $42.7)$ & $44.2)$ & $<0.001^{\mathrm{b}}$ \\
\hline Diameter of descending & $28.7(26.1$, & $31.9(27.9$, & $32.1(29.3$, & $<0.001^{\mathrm{b}}$ \\
aorta (mm) & $31.7)$ & $34.6)$ & $35.1)$ & \\
Hematoma thickness (mm) & $9.03(8.12$, & $7.32(6.62$, & $6.27(5.56$, & $<0.001^{\mathrm{b}}$ \\
\hline
\end{tabular}

ACEI, angiotensin-converting enzyme inhibitor; ARB, angiotensin II receptor blocker; BMI, body mass index; OSA, obstructive sleep apnea; ULP, ulcer-like projection.

a: Results of the normality test (Kolmogorov-Smirnov test) and the Levene's test results of homogeneity of variances between the OSA group and the non-OSA group are presented in the Supplement 1. Quantitative variables are present as mean \pm standard deviations if normally distributed and median ( $25^{\text {th }}$ percentile, $75^{\text {th }}$ percentile) if abnormally distributed. $\mathrm{b}$ : The details of the independent-samples Kruskal-Wallis test and pairwise comparisons of three groups are presented in the Supplement 2.

$\mathrm{c}_{\mathrm{S}}$ In the Stanford system, all lesions involve the ascending aorta are defined as type A and those do not involve the ascending aorta, including the aortic arch and descending aorta, are classified as type B. 
Table 2 Disease Progressions, Treatments and Outcomes

\begin{tabular}{|c|c|c|c|c|}
\hline Variables & $\begin{array}{l}\text { Group A } \\
(\mathrm{n}=572)\end{array}$ & $\begin{array}{l}\text { Group B } \\
(\mathrm{n}=191)\end{array}$ & $\begin{array}{l}\text { Group C } \\
(\mathrm{n}=331)\end{array}$ & $P$ value \\
\hline $\begin{array}{l}\text { Aorta-related adverse events during the } \\
\text { acute phase, } n(\%)\end{array}$ & $\begin{array}{c}95 \\
(16.6 \%)\end{array}$ & $15(7.9 \%)$ & $10(3.0 \%)$ & $<0.001^{\mathrm{C}}$ \\
\hline $\begin{array}{l}\text { Hematoma thickening (thickness } \geq 10 \\
\mathrm{~mm}), \mathrm{n}(\%)\end{array}$ & $2(0.3 \%)$ & $0(0 \%)$ & $1(0.3 \%)$ & 0.721 \\
\hline Development of ULPs, n (\%) & $\begin{array}{c}81 \\
(14.2 \%)\end{array}$ & $13(6.8 \%)$ & $7(2.1 \%)$ & $<0.001^{\mathrm{C}}$ \\
\hline Development of aortic dissection, $\mathbf{n}(\%)$ & $10(1.7 \%)$ & $2(1.0 \%)$ & $2(0.6 \%)$ & 0.292 \\
\hline $\begin{array}{l}\text { Aortic } \\
\text { aneurysm/pseudoaneurysm development, } \mathrm{n} \\
\text { (\%) }\end{array}$ & $2(0.3 \%)$ & $0(0 \%)$ & $0(0.0 \%)$ & 0.273 \\
\hline
\end{tabular}

Treatment

Surgery, n (\%) $\quad 11(1.9 \%) \quad 2(1.0 \%) \quad 0(0.0 \%) \quad 0.036^{\mathrm{c}}$

TEVAR $^{\mathrm{a}}, \mathrm{n}(\%)$

84

Died after Sugery/TEVAR, n (\%)

$(14.7 \%)$

$12 \quad 2(13.3 \%) \quad 1(10.0 \%) \quad 0.866$

Late follow-up, $\mathbf{n}$

$(12.6 \%)$

$560 \quad 189 \quad 330$

Median follow-up time (months)

44.2

$(42.0-$

46.4)

Stable/resolution of hematoma, $\mathbf{n}(\%)$

393

(70.2\%)

167

(29.8\%)

$13(6.9 \%)$

$10(3.0 \%)$

$<0.001^{\mathrm{c}}$

Aorta-related adverse events during the

follow-up period, $n(\%)$

43.0

(38.1-

40.6

47.9)

(36.9-

44.4)

Hematom
$\mathrm{mm}), \mathrm{n}(\%)$

Development of ULPs, $\mathbf{n}(\%)$

127

$\begin{array}{lr} & (22.7 \%) \\ \text { Development of aortic dissection, } \mathbf{n}(\%) & 21(3.8 \%)\end{array}$

(87.3\%)

309
$(93.6 \%)$

$<0.001^{\mathrm{c}}$

$18(9.5 \%) \quad 10(3.0 \%)<0.001^{\mathrm{c}}$

Aortic aneurysm/pseudoaneurysm, $n$ (\%)

$9(1.6 \%)$

$3(1.6 \%)$

$6(1.8 \%) \quad 0.130$

Reintervention ${ }^{\mathrm{b}}$, $\mathrm{n}(\%)$

All-cause death cases, $\mathbf{n}$ (\%)

152

(27.1\%)

62

(11.1\%) (11.1\%)

$2(1.1 \%)$

$3(0.9 \%)$

0.633

$21(6.4 \%)<0.001^{\mathrm{C}}$

$(12.7 \%)$

$2(0.6 \%) \quad 0.191$

Aorta-related death cases, $\mathrm{n}(\%)$

(11.1\%)

$17(5.2 \%)<0.001^{\mathrm{c}}$

Non-aorta-related death case, n (\%)

$45(8.0 \%) \quad 15(7.9 \%)$

$14(4.2 \%)$

$0.002^{\mathrm{c}}$

$17(3.1 \%) \quad 6(3.2 \%) \quad 10(3.0 \%)$

$<0.001^{\mathrm{c}}$

0.995

TEVAR, thoracic endovascular aortic repair; ULP: Ulcer-like projection.

a: Valiant (Medtronic, Inc, Minneapolis, Minn); Ankura (Lifetechmed, Inc, Shenzhen, China);

$\mathrm{b}$ : Including TEVAR or open surgery.

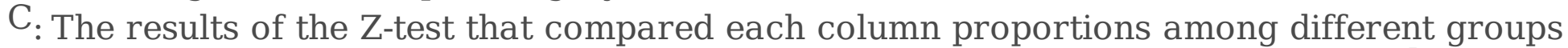
and calculated the adjusted p-value (Bonferroni method) are presented in the Supplement 3.

Table 3 Variables Associated with Aorta-Related Adverse Events and Aorta-Related Mortality ${ }^{a b}$ 
sgistic regression analyses: significant predictors for aorta-related adverse events in the ;ute phase

Variables

Univariate analysis

Adjusted

multivariable

analysis

\begin{tabular}{|c|c|c|c|c|c|c|}
\hline & \multirow{2}{*}{\multicolumn{2}{|c|}{ Unadjusted }} & & & \multirow[b]{2}{*}{ OR $(95 \% \mathrm{CI})$} & \multirow[b]{2}{*}{$P$ value } \\
\hline & & & $\begin{array}{c}\text { Adjusted OR } \\
(95 \% \mathrm{CI})\end{array}$ & $P$ value & & \\
\hline $\begin{array}{l}\text { Neutrophil } \\
\text { lymphocyte ratio }\end{array}$ & $\begin{array}{l}1.14(1.11- \\
1.17)\end{array}$ & $<0.001$ & $\begin{array}{l}1.14 \\
(1.10-\end{array}$ & $<0.001$ & & - \\
\hline $\begin{array}{l}\text { Eosinophils per } 0.1 \\
\text { (10^9/L) }\end{array}$ & $\begin{array}{l}0.15(0.09- \\
0.25)\end{array}$ & $<0.001$ & $\begin{array}{l}0.16 \\
(0.10- \\
0.26)\end{array}$ & $<0.001$ & $\begin{array}{c}0.12 \\
(0.06- \\
0.22)\end{array}$ & $<0.001$ \\
\hline $\begin{array}{l}\text { C-reactive protein on } \\
\text { admission }(\mathrm{mg} / \mathrm{L})\end{array}$ & $\begin{array}{l}1.18(1.15- \\
1.21)\end{array}$ & $<0.001$ & $\begin{array}{l}1.18 \\
(1.15- \\
1.22)\end{array}$ & $<0.001$ & $\begin{array}{l}1.10 \\
(1.05- \\
1.14)\end{array}$ & $<0.001$ \\
\hline $\begin{array}{l}\text { D-dimer on admission } \\
(\mathrm{ug} / \mathrm{mL})\end{array}$ & $\begin{array}{l}7.34(4.97- \\
10.85)\end{array}$ & $<0.001$ & $\begin{array}{r}7.32 \\
(4.93- \\
11.02)\end{array}$ & $<0.001$ & - & - \\
\hline $\begin{array}{l}\text { Maximum ascending } \\
\text { aorta diameter, mm }\end{array}$ & $\begin{array}{l}1.29(1.21- \\
1.38)\end{array}$ & 0.025 & $\begin{array}{l}1.41 \\
(1.31- \\
1.52)\end{array}$ & $<0.001$ & $\begin{array}{l}1.41 \\
(1.18- \\
1.68)\end{array}$ & $<0.001$ \\
\hline $\begin{array}{l}\text { Maximum descending } \\
\text { aorta diameter, } \mathrm{mm}\end{array}$ & $\begin{array}{c}1.36(1.27- \\
1.44)\end{array}$ & 0.066 & $\begin{array}{l}1.53 \\
(1.41- \\
1.67)\end{array}$ & $<0.001$ & $\begin{array}{l}1.52 \\
(1.31- \\
1.76)\end{array}$ & $<0.001$ \\
\hline $\begin{array}{l}\text { Maximum hematoma } \\
\text { thickness, mm }\end{array}$ & $\begin{array}{l}1.82(1.52- \\
2.18)\end{array}$ & 0.202 & $\begin{array}{l}1.69 \\
(1.40- \\
2.04)\end{array}$ & $<0.001$ & $\begin{array}{l}2.00 \\
(1.43- \\
2.81)\end{array}$ & $<0.001$ \\
\hline
\end{tabular}

Jx proportional hazard models: significant variables associated with aorta-related adverse ents during the follow-up period Variables

Univariate analysis

Adjusted multivariable analysis

\begin{tabular}{ccclcc}
\hline Unadjusted & $P$ value & $\begin{array}{c}\text { Adjusted HR } \\
\text { (95\% CI) }\end{array}$ & $P$ value & & $\begin{array}{c}\text { HR (95\% } \\
\text { HR (95\% CI) }\end{array}$
\end{tabular}

\begin{tabular}{|c|c|c|c|c|c|c|}
\hline $\begin{array}{l}\text { Neutrophil } \\
\text { lymphocyte ratio }\end{array}$ & $\begin{array}{c}1.06(1.04- \\
1.09)\end{array}$ & $<0.001$ & $\begin{array}{l}1.05 \\
(1.03-\end{array}$ & $<0.001$ & - & - \\
\hline $\begin{array}{l}\text { Eosinophils per } 0.1 \\
\left(10^{\wedge} 9 / \mathrm{L}\right)\end{array}$ & $\begin{array}{l}0.56(0.48- \\
0.66)\end{array}$ & $<0.001$ & $\begin{array}{l}0.59 \\
(0.50- \\
0.70)\end{array}$ & $<0.001$ & $\begin{array}{c}0.61 \\
(0.51- \\
0.73)\end{array}$ & $<0.001$ \\
\hline $\begin{array}{l}\text { C-reactive protein on } \\
\text { admission }(\mathrm{mg} / \mathrm{L})\end{array}$ & $\begin{array}{c}1.01 \\
(1.00-1.02)\end{array}$ & 0.002 & $\begin{array}{l}1.01 \\
(1.00- \\
1.02)\end{array}$ & 0.056 & - & - \\
\hline $\begin{array}{l}\text { D-dimer on admission } \\
\text { (ug/mL) }\end{array}$ & $\begin{array}{l}1.53(1.34- \\
1.75)\end{array}$ & $<0.001$ & $\begin{array}{l}1.43 \\
(1.23- \\
1.66)\end{array}$ & $<0.001$ & - & - \\
\hline $\begin{array}{l}\text { Maximum ascending } \\
\text { aorta diameter, } \mathrm{mm}\end{array}$ & $\begin{array}{l}0.93(0.89- \\
0.97)\end{array}$ & $<0.001$ & $\begin{array}{l}0.95(0.91- \\
0.99)\end{array}$ & 0.011 & - & - \\
\hline $\begin{array}{l}\text { Maximum descending } \\
\text { aorta diameter, } \mathrm{mm}\end{array}$ & $\begin{array}{c}0.94 \\
(0.91-0.97)\end{array}$ & 0.001 & $\begin{array}{c}0.96 \\
(0.92- \\
0.99)\end{array}$ & 0.016 & - & - \\
\hline $\begin{array}{l}\text { Maximum hematoma } \\
\text { thickness, mm }\end{array}$ & $\begin{array}{l}1.45(1.28- \\
1.63)\end{array}$ & $<0.001$ & $\begin{array}{l}1.36 \\
(1.20- \\
1.55)\end{array}$ & $<0.001$ & $\begin{array}{l}1.22 \\
(1.06- \\
1.39)\end{array}$ & 0.005 \\
\hline
\end{tabular}


Jx proportional hazard models: significant variables associated with aorta-related mortality uring the follow-up period

Variables

Univariate analysis

Adjusted multivariable

analysis

\begin{tabular}{|c|c|c|c|c|c|c|}
\hline & \multirow{2}{*}{\multicolumn{2}{|c|}{ Unadjusted }} & \multirow{2}{*}{\multicolumn{2}{|c|}{$\begin{array}{c}\begin{array}{c}\text { Adjusted HR } \\
(95 \% \mathrm{CI})\end{array} \\
P \text { value }\end{array}$}} & \\
\hline & & & & & $\begin{array}{l}\text { HR ( } 95 \% \\
\text { CI) }\end{array}$ & $P$ value \\
\hline $\begin{array}{l}\text { Neutrophil } \\
\text { lymphocyte ratio }\end{array}$ & $\begin{array}{c}1.07(1.03- \\
1.11)\end{array}$ & 0.001 & $\begin{array}{l}1.07 \\
(1.03- \\
1.11)\end{array}$ & 0.001 & - & - \\
\hline $\begin{array}{l}\text { Eosinophils per } 0.1 \\
\left(10^{\wedge} 9 / \mathrm{L}\right)\end{array}$ & $\begin{array}{l}0.45(0.32- \\
0.64)\end{array}$ & $<0.001$ & $\begin{array}{c}0.46 \\
(0.32- \\
0.65)\end{array}$ & $<0.001$ & $\begin{array}{c}0.24 \\
(0.15- \\
0.40)\end{array}$ & $<0.001$ \\
\hline $\begin{array}{l}\text { C-reactive protein on } \\
\text { admission }(\mathrm{mg} / \mathrm{L})\end{array}$ & $\begin{array}{l}0.91(0.81- \\
1.01)\end{array}$ & 0.083 & $\begin{array}{c}1.01 \\
(0.99- \\
1.03)\end{array}$ & 0.248 & & \\
\hline $\begin{array}{l}\text { D-dimer on admission } \\
\text { (ug/mL) }\end{array}$ & $\begin{array}{l}1.06(0.98- \\
1.13)\end{array}$ & 0.125 & $\begin{array}{l}1.38 \\
(1.06- \\
1.78)\end{array}$ & 0.015 & - & - \\
\hline $\begin{array}{l}\text { Maximum ascending } \\
\text { aorta diameter, } \mathrm{mm}\end{array}$ & $\begin{array}{l}1.09(1.01- \\
1.17)\end{array}$ & 0.028 & $\begin{array}{c}0.92 \\
(0.85- \\
0.99)\end{array}$ & 0.030 & $\begin{array}{c}1.12 \\
(1.02- \\
1.23)\end{array}$ & 0.021 \\
\hline $\begin{array}{l}\text { Maximum descending } \\
\text { aorta diameter, mm }\end{array}$ & $\begin{array}{l}1.03(0.99- \\
1.07)\end{array}$ & 0.136 & $\begin{array}{c}0.97 \\
(0.90- \\
1.04)\end{array}$ & 0.337 & & \\
\hline $\begin{array}{l}\text { Maximum hematoma } \\
\text { thickness, mm }\end{array}$ & $\begin{array}{l}1.54(1.09- \\
2.17)\end{array}$ & 0.014 & $\begin{array}{l}2.55 \\
(1.95- \\
3.33)\end{array}$ & $<0.001$ & $\begin{array}{l}3.25 \\
(2.36- \\
4.46)\end{array}$ & $<0.001$ \\
\hline
\end{tabular}

CI: confidence interval; HR: hazard ration; OR: odds ratio.

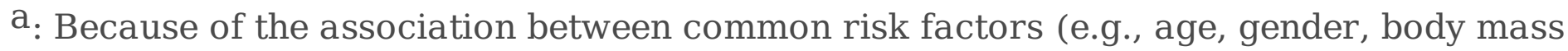
index, hypertension, dyslipidemia, coronary heart disease, and obstructive sleep apnea) and aortic disease, both the Logistic regression analyses and Cox proportional hazard models were adjusted on presence of age, gender, body mass index, hypertension, dyslipidemia, coronary heart disease, obstructive sleep apnea and antihypertension therapy (using of angiotensin-converting enzyme inhibitor, angiotensin II receptor blocker, $\beta$-blockers, and calcium antagonists, diuretic, urapidil, and nitrates).

$\mathrm{b}$ : The collinearity test was performed to check the collinearity of variables in the model. We also provide the results of the collinearity test of variables in the Supplement 4.

\section{Figures}




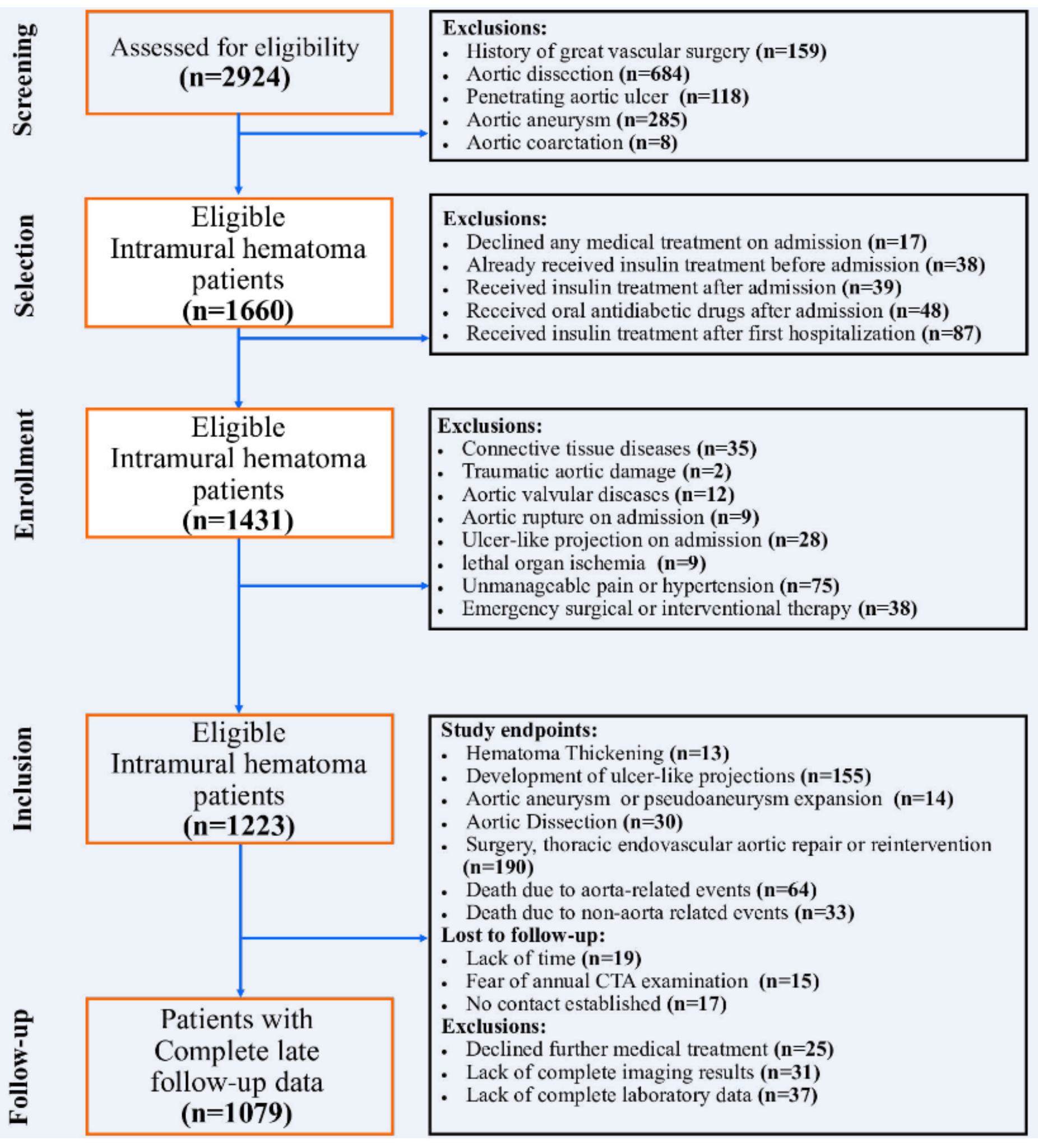

\section{Figure 1}

CONSORT Diagram The CONSORT diagram of the patient selection process is shown in this figure. From January 2000 to December 2020, a total of $1094 \mathrm{IMH}$ patients who received the "wait-and-watch strategy" in a single institution were included in this study and the late follow-up comprised 1079 patients. Patients who refused medical treatment, those who did not have CTA images to estimate the 
evolution of IMH, those who did not have complete laboratory data, and those who were lost to follow-up were regarded as missing data

(\%)

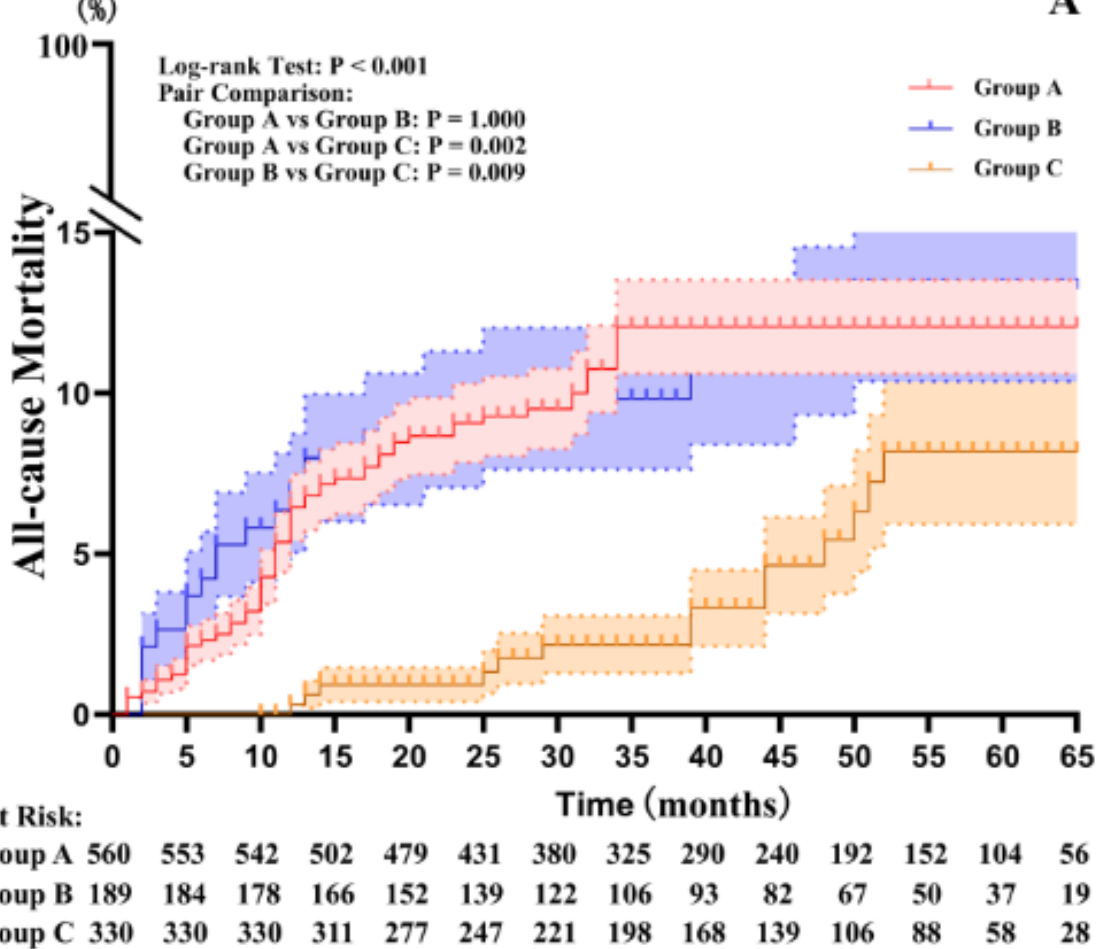

(\%)

B

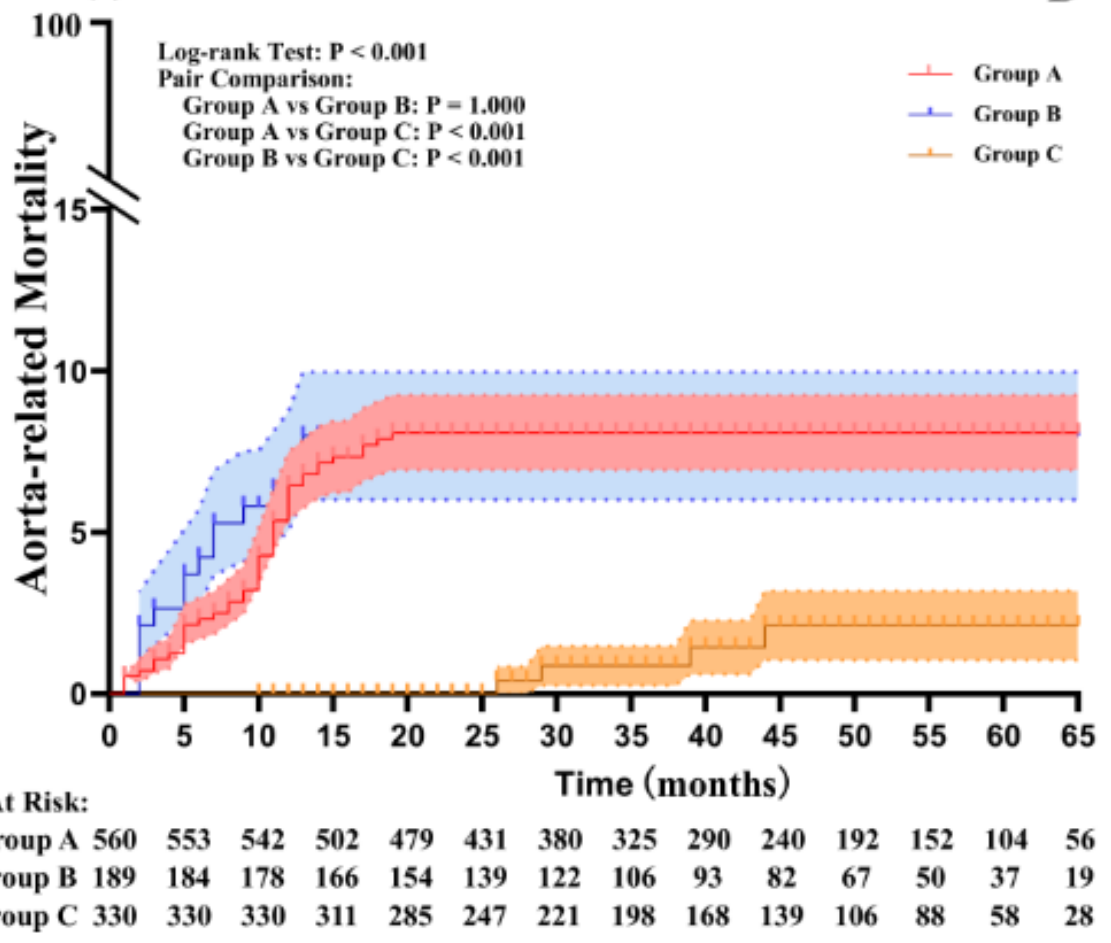

Figure 2

Kaplan-Meier Survival Analysis Results (A) The Kaplan-Meier survival analysis revealed a significant decrease in the all-cause mortality rates in the group $\mathrm{C}$ compared with that in the group $\mathrm{B}$ and $\mathrm{C}$ 
$(P<0.001)$. (B) The Kaplan-Meier survival analysis revealed a significant decrease in the aorta-related mortality rates in the group $C$ compared with that in the group $B$ and $C(P<0.001)$.

\section{Supplementary Files}

This is a list of supplementary files associated with this preprint. Click to download.

- Supplement1.docx

- Supplement2.docx

- Supplement3.docx

- Supplement4.docx 